\title{
Design and Fabrication of a Special Purpose Hydraulic Press Performing Bending Operation
}

\author{
Shivasheesh Kaushik \\ Assistant Professor, in Department of MECHANICAL Engineering, AGI (Amarpali Group of Institute) Haldwani, Uttarakhand, India
}

\begin{abstract}
Hydraulics has proven to be the most efficient and economical system adaptable to aviation. First used by the ancient Greeks as a means of elevating the stages of their amphitheaters, the principles of hydraulics were explained scientifically by the seventeenth century scholars Pascal and Boyle. The laws discovered by these two men regarding the effects of pressure and temperature on fluids and gases in confined areas form the basis of the principle of mechanical advantage; in other words, the "why and how" of hydraulics. The word "hydraulic" is derived from two Greek words: "hydro" meaning liquid or water and "Aulis" meaning pipe or tubing. "Hydraulic," therefore, is an adjective implying that the word it modifies is in some major way concerned with liquids. Examples can be found in the everyday usage of "hydraulic" in connection with familiar items such as automobile jacks and brakes. As a further example, the phrase "hydraulic freight elevator" refers to an elevator ascending and descending on a column of liquid instead of using cables and a drum. On the other hand, the word "hydraulics" is the generic name of a subject. According to the dictionary "hydraulics" is defined as a branch of science that deals with practical applications (such as the transmission of energy or the effects of flow) of a liquid in motion.
\end{abstract}

Keywords: Special purpose machine, Bending operation, Hydraulic concept

\section{Present Work}

Here we are designing a hydraulic punching \& bending machine.

We followed following some steps in this project are:-

1) Study the concept of hydraulic machine and hydraulic press.

2) Selection of the product which we are making through this machine.

3) Selection of the operations which we have to perform on it.

4) Selection of the dies which we use for it.

5) Selection of different number of part through which we create machine.

6) Selection of material for each part.

7) Calculation and the forces analysis of those parts.

8) Selection of the software on which these parts are design.

9) Making the different views of that part in the auto-cad software.

10)Making the design of those parts in pro-e software and solid work software.

11)Finally assembly of that part should do in the pro-e software.

Our hydraulic press or machine which we are making here depends on Pascal's principle: the pressure throughout a closed system is constant. One part of the system is a piston acting as a pump, with a modest mechanical force acting on a small cross-sectional area; the other part is a piston with a larger area which generates a correspondingly large mechanical force. Only small-diameter tubing (which more easily resists pressure) is needed if the pump is separated from the press cylinder. Pascal's law: It states that pressure exerted anywhere in a confined incompressible fluid is transmitted equally in all directions throughout the fluid such that the pressure ratio (initial difference) remains the same.
Selection of the product which we are making through this machine

It is an Special purpose machinery, as the name suggests, is constructed for some very particular purpose. These machines are not built en masse as is the case with most types of machinery and are custom made. Effectively, these machines are made from scratch without any preconceived concepts or notions. It is also possible for them to be special purpose machines that are designed to be a part of a bigger system or machine. In these cases, the special purpose machine would be created to serve a very particular purpose in the bigger scheme of things. The main function and objective of this machine is to manufacturing a complete design which is used in our houses as a inner supporting housing for the circuit boards.

Selection of the operations which we have to perform on it:

Through this machine we perform basically two operations simultaneously. First is for punching hole or in other words piercing and second is for bending the sheet.

\section{1) For punching holes}

Here in this operation we are cutting 5 holes in a sheet one by one but these five holes are cut in a single stroke of piston. This can be achieve with the help of designing, how we design the punch, here we design the punch in such a way that, we give a gap of $2 \mathrm{~cm}$ between the length each respected punch the time interval for reaching the punch to sheet is vary due this method of designing, So in this way sheet will come in contact with punch only one time until the next hole does not cut. By this way we required less force for cutting holes.

\section{2) For bending the sheet}

Here we use wiping die for bending sheets. Wiping die is also known as flanging. One edge of the sheet is bent to 90 


\section{International Journal of Science and Research (IJSR) \\ ISSN (Online): 2319-7064}

Index Copernicus Value (2013): 6.14 | Impact Factor (2014): 5.611

degree while the other end is restrained by the material itself and by the force of blank holder and pad. The flange length easily changed and the bend angle can be controlled by the stroke position of the punch. Here the new thing which we are going to do is four corner bending with the help of the punch which we are designing by our self.

\section{Selection of the dies which we use for our machine:}

For our hydraulic machine we use combination die which perform piercing as well as bending operation simultaneously in a single stroke of a piston. This type of die is similar to that of a compound die except that here non cutting operation such as bending, piercing and forming are also done or includes as a part of operation. For our die we use cast iron. Here we designing, the separate punch and dies for bending and piercing in the pro-e and solid works software. After completing it we attached both the punch and the die in a same plate and converted that into a combination die which do their respective operation simultaneously in a single stroke of piston.

Selection of different number of part and the material through which we create machine:

Cylinder, Piston, Piston ring, Piston pin, Plunger, Punch for piercing purpose, Die for piercing purpose, Punch for bending purpose, Die for bending purpose, Base stand Cylinder supporting stand, Cylinder clamper, Supporting stand clamper, Bench for holding motor and pump, Motor, Pump , Fluid container, Pressure pipes , Nut and Bolts , clutcher of pressure pipes.

\section{Selection of Material}

\section{Punch And Die Material ${ }^{(1)}$ :}

Punching Tool Material For Punching Operation-EN31 Composition: $\mathrm{C}=0.95-1.20 \%, \mathrm{Si}=0.10-0.35 \%, \mathrm{Mn}=0.30$ $0.35 \%, \mathrm{Cr}=1-1.6 \%$.

\section{Properties of EN31-}

Ultimate Tensile Strength=900-1100MPa

Tensile Yield Strength $=650-750 \mathrm{MPa}$

i-High Carbon Alloy Steel.

ii-High Toughness And Tensile Strength.

\section{Punching Die Material-EN30 \\ Composition: $\mathrm{C}=0.26-0.34 \%, \mathrm{Si}=0.10-0.35 \%, \mathrm{Mn}=0.40$ - $0.60 \%, \mathrm{Cr}=1.10-1.40 \%, \mathrm{Ni}=1.3-1.86 \%, \mathrm{Mo}=0.20-0.40 \%$.}

\section{Properties of EN30-}

Ultimate Tensile Strength $=850-1000 \mathrm{MPa}$

Tensile Yield Strength $=650 \mathrm{MPa}$

Percentage Elongation $(\% \mathrm{EL})=13$

Brinell Hardness Number $(\mathrm{BHN})=250$

$\mathrm{i}-\mathrm{EN} 30$ is a versalite high strength alloy.

ii-High toughness.

iii-A high strength alloy having a good combination of strength and impact properties

\section{Punching Tool Material For Bending Operation-EN31}

Properties of EN31-

Ultimate Tensile Strength $=900-1100 \mathrm{MPa}$
Tensile Yield Strength $=650-750 \mathrm{MPa}$

i-High Carbon Alloy Steel.

ii-High Toughness And Tensile Strength.

\section{Bending Die Material-EN30}

\section{Properties Of EN30-}

Ultimate Tensile Strength $=850 \mathrm{MPa}$

Tensile Yield Strength $=650 \mathrm{MPa}$

Percentage Elongation $(\% \mathrm{EL})=13$

Brinell Hardness Number $(\mathrm{BHN})=250$

i. EN30 is a versalite high strength alloy.

ii. High toughness.

iii. A high strength alloy having a good combination of strength and impact properties

\section{Punch Holder Material- Mild Steel Sheet (Low Carbon} Steel)

Coposition: $\mathrm{C}=0.05-0.20 \%$,

Ultimate Tensile Strength $=400-450 \mathrm{MPa}$

Shear Strength $=200 \mathrm{MPa}$

\section{Clamping Material-Nuts And Bolts:}

Nut Material Specifications:ASTM A194 Grade A-Low

Carbon Non-Geat Treat,Heavy Pattern.

Bolt Specifications:ASTM A307 Grade B7-Chromium-

Molybdenum Steel.

\section{Spring Material-Carbon-manganese Spring Steels} Composition: $\mathrm{C}=0.45-0.65 \%, \mathrm{Si}=0.1-0.35 \%, \mathrm{Mn}=0.5-1.0 \%$. Brinell Hardness Number $(\mathrm{BHN})=350$

Pressure Pipes: SAE 100R2AT,1/2",276bar,4000psi. Iron Channel Beam: Mild Steel

\section{Different types of Material Can Be Used For Making the} Product Are:

\section{1-Aluminium}

Properties Of Aluminum ${ }^{(1)}$ :

Ultimate Tensile Strength $=200 \mathrm{MPa}$, Tensile Yield Strength $=185 \mathrm{MPa}$, Shear Strength $=110 \mathrm{MPa}$, Shear Modulus $=25 \mathrm{GPa}$, Modulus of Elasticity $=68.9 \mathrm{GPa}$, Density $=2.73 \mathrm{~g} / \mathrm{cc}$, Thermal Conductivity, $\mathrm{k}=154 \mathrm{~W} / \mathrm{mk}$, Melting Point Temp. $=643-654^{\circ} \mathrm{C}$, Specific Heat Capacity $=0.843 \mathrm{j} / \mathrm{g}{ }^{\circ} \mathrm{C}$, Poisson's ratio, $\mu=0.33$.

\section{2-Copper \\ Properties Of Copper ${ }^{(1)}$ :}

Ultimate Tensile Strength $=220 \mathrm{MPa}$, Tensile Yield Strength $=140 \mathrm{MPa}$, Shear Strength $=172 \mathrm{MPa}$, Shear Modulus $=48 \mathrm{GPa}$, Modulus Of Elasticity $=120 \mathrm{GPa}$, Density $=8.02 \mathrm{~g} / \mathrm{cc}$, Thermal Conductivity, $\mathrm{k}=410 \mathrm{~W} / \mathrm{mk}$, Melting Point Temperature $=1357.77 \mathrm{~K} \quad\left(1084.62^{\circ} \mathrm{C}\right)$, Poisson's ratio, $\mu=0.35$.

\section{3-Brass}

Properties Of Brass ${ }^{(1)}$ :

Ultimate Tensile Strength $=345 \mathrm{MPa}$, Tensile Yield Strength $=135 \mathrm{MPa}$, Shear Strength $=235 \mathrm{MPa}$, Shear Modulus $=34 \mathrm{GPa}$, Modulus Of Elasticity $=97 \mathrm{GPa}$, Density $=8.47 \mathrm{~g} / \mathrm{cc}$, Thermal Conductivity, $\mathrm{k}=115 \mathrm{~W} / \mathrm{mk}$, 


\section{International Journal of Science and Research (IJSR) \\ ISSN (Online): 2319-7064}

Index Copernicus Value (2013): 6.14 | Impact Factor (2014): 5.611

Melting Point Temperature $=885-900^{\circ} \mathrm{C}$, Machinability $=$ $100 \%$, Poisson's ratio, $\mu=0.34$

\section{Problem Formulation/Design}

For the sheet metal work in the project, we use Aluminum sheet of thickness $2 \mathrm{~mm}$ (millimeter), because of ease of operation performing on it. And the grade 3003-H18 of aluminum is considered according to design aspect. Grade 3003 is commercially pure and the most widely used aluminum alloy. Its uses include cooking utensils, cabinets, mailboxes, fan blades, decorative trim, awnings and chemical equipment.

\section{Calculation and the forces analysis of those parts:}

Here we calculated a number of calculation and forces related to our design of machine which are as follows:-

1) Calculating the bore and length of the cylinder and select the material for it.

2) Calculating the thickness of cylinder wall.

3) Calculating the stress in cylinder wall.

4) Calculating the length of studs and cylinder head.

5) Select the material for the piston.

6) Calculating the thickness of piston head, piston rib and cup.

7) Calculating the die and thickness of piston ring and material selection for it.

8) Calculation related to the piston barrel

9) Calculation related to the piston skirt.

10) Calculation related to the piston pin.

11) Calculation related to piston and material selection for it.

12) Calculation related to the force generation by the motor and pump.

13) Calculation related to cutting force which appears on the sheet.

\section{Design Consideration}

Sheet used-Aluminum alloy $3003-\mathrm{H}_{18}{ }^{(2)}$

Shear strength $(\mathrm{Ss})=110 \mathrm{MPa}$, UTS $=$ Ultimate Tensile

Strength $=200 \mathrm{MPa}$, Thickness of $\operatorname{sheet}(\mathrm{t})=2 \mathrm{~mm}$

\section{Punch and Die Sizes:}

Punch Diameter $\left(D_{\mathrm{p}}\right)=2.7 \mathrm{~cm}=27 \mathrm{~mm}$

For a round hole of diameter $\mathrm{D}_{\mathrm{h}}$ :

Hole punch diameter $\left(D_{\mathrm{h}}\right)=27 \mathrm{~mm}$

Hole die diameter $=\mathrm{D}_{\mathrm{h}}+2 \mathrm{c}=27+2(0.5)=28 \mathrm{~mm}$

Where, $c=$ clearance

Bending Force ${ }^{[3]} \mathrm{F}_{\mathrm{b}}=\left(\mathrm{K} * \mathrm{UTS} * \mathrm{~L}^{*} \mathrm{t}^{\wedge} 2\right) / \mathrm{W}^{(2)}$

$\mathrm{F}_{\mathrm{b}}=(0.33 * 200 * 440 * 2 * 2) / 27=4302 \mathrm{~N}$ and $\mathrm{F}_{\mathrm{b}}=4.3 \mathrm{KN}$

Where $\mathrm{K}=0.33$ for wiping bending, UTS=Ultimate Tensile Strength of sheet $=200 \mathrm{MPa}$

$\mathrm{L}=$ Length of Bent Part, $\mathrm{T}=\mathrm{Blank}$ Thickness $=2 \mathrm{~mm}, \mathrm{~W}=\mathrm{Width}$ of Die-opening

\section{Different Parts of Hydraulic Press}

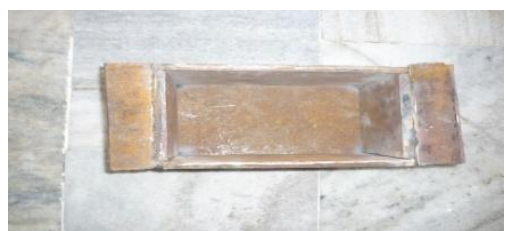

Figure 34: Punch for Bending

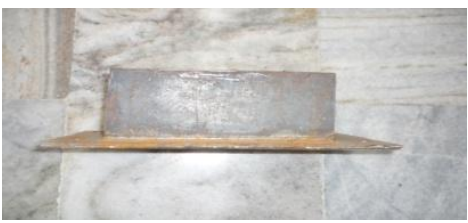

Figure 33: Bending die

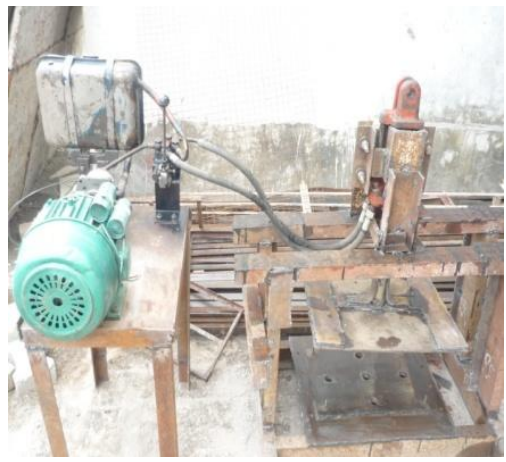

Figure 4: Front View of Machine

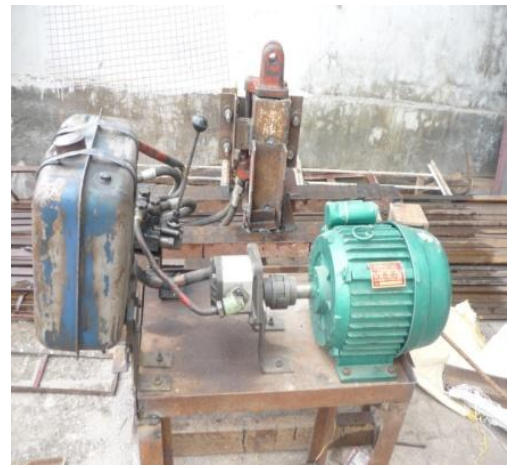

Figure 5: Assembly of Fuel pump cylinder \& motor

\section{Result}

Punching or cutting force $=93.3 \mathrm{KN}$, Bending force $=4.3 \mathrm{KN}$, Cylinder Pressure $=276 \mathrm{bar}$ (4000PSI), Cylinder Force $=138.73 \mathrm{KN}$, Capacity of press $=14.1$ tons, Capacity of pump $=1.0 \mathrm{gal} / \mathrm{min}=3.72 \mathrm{lt} / \mathrm{min}$, Magnitude of electric motor $=2 \mathrm{hp}=1.5 \mathrm{kw}$

\section{Conclusion}

The hydraulic bending machine is successfully enrolled and is calculated properly. In this we have introduce a special purpose hydraulic model of Punching and Bending machine and we have showed theoretically how the hydraulic model of special purpose punching machine economically and exactly works. First of all we have done a survey of literature review of the machine, and market survey for the working and constructional detailed. Then we have calculated the formulas for the design of the different parts 


\section{International Journal of Science and Research (IJSR) \\ ISSN (Online): 2319-7064}

Index Copernicus Value (2013): 6.14 | Impact Factor (2014): 5.611

of hydraulic cylinder so that we can calculate the capacity of the hydraulic punching and bending machine and Finally fabricate the machine to perform the operation on the aluminium sheet to produce the final product. We have seen how the Hydraulic systems allow users to accurately wield large amounts of power with little input force. And with the combination die two operation are performed simultaneously. So we can say that the hydraulic system of special purpose punching and bending machine is quite economical as compare to the other alternative.

\section{References}

[1] Metals Handbook VOL.2 ASM International $10^{\text {th }}$ Ed.1990.

[2] Metals Handbook Howard E.Boyer \& Timothy L.Gall,Eds,American Society For Metals,Materials, OH, 1985.

[3] Jain R.K, 'Production Technology', (Khanna Publishers, $17^{\text {th }}$ Ed.2009) and Khurmi, R.S.; and Gupta, J.K. 1997. A textbook of machine design. Eurasia Publ., New Delhi, India.

[4] Miller Fluid Power H-Series Hydraulic Cylinder Catalog, , September 2003. Livonia, MI: Miller Fluid Power and Bhandari V P -Design of Machine Elements, Tata McGraw-Hill Education(2010) 